\title{
Lineaments study using aeromagnetic data over parts of southern Bida basin, Nigeria and the surrounding basement rocks
}

\author{
John U. Megwara ${ }^{1}$ and Emmanuel E. Udensi ${ }^{2}$ \\ ${ }^{1}$ Nigerian Geological Survey Agency, P.M.B. 2007, Kaduna, Nigeria \\ ${ }^{2}$ Federal University of Technology, P.M.B.65, Minna, Nigeria \\ *Corresponding authorE-mail: megwarauj@yahoo.com
}

\begin{abstract}
Trend analysis using aeromagnetic data was carried out over parts of the southern Bida basin, Nigeria and the surrounding basement rocks. Qualitative analysis of the total magnetic intensity map was carried out. Magnetic lineaments were inferred using the Euler deconvolution and analytic signal techniques. Deductions made from the study are; the Romanche fracture zone passed through the study area and the prominent trends of lineaments are the northsouth, northeast-southwest and northwest-southeast directions.
\end{abstract}

Keywords: Analytic signal, Euler deconvolution, lineaments, magnetics

\section{Introduction}

The study area covers parts of southern Bida basin, Nigeria and the surrounding basement rocks. The survey location is bounded by a longitude range of $4.5^{\circ} \mathrm{E}$ to $8.0^{\circ} \mathrm{E}$ and latitude range of $8.0^{\circ} \mathrm{N}$ to $9.0^{\circ} \mathrm{N}$, with an areal extent of about $33,275 \mathrm{~km}^{2}$. Figure 1 shows the research area in black outline (having the shape of an irregular octagon).

\section{Geology of the study area}

The geology of the study area is shown in Figure 2. In the southern Bida basin section, the Pre-Cambrian to lower Paleozoic basement gneisses and schist is overlain by alternating shales, siltstones, claystones and sandstones [9, 10]. The sandstones (Nupe) consist of slightly cemented fine to coarse-grained sandstones and siltstones with interbedded thin beds of carbonaceous shales and clays. The southern Bida basin section of the study area; forms part of the larger Bida basin. The successions in the southern Bida basin consist of the basal Lokoja Formation, overlain by the Patti Formation and capped by the Agbaja Formation. The basal Lokoja Formation is a sequence of matrix supported conglomerates and sandstones overlying the Pre-Cambrian to lower Paleozoic basement. Depositional environments are predominantly within fluvial systems of a continental setting. The Patti Formation consists of dark grey carbonaceous shales; mudstones and siltstones representing flood plains to shallow marine deposits with likely organic rich intervals. Agbaja Formation is made up of ferruginised oolitic and kaolinitic mudstone of a marginal environment [2]. The surrounding Pre-Cambrian basement rocks consist of a suit of Pre-Cambrian gneisses, migmatites and metasedimentary schist crosscut by intrusive granitoids [13]. The Pre-Cambrian basement rocks experienced severe deformation during the late Pan-African phase (600 m.y.), and developed megashears that were reactivated during the late Campanian-Maastrichtian [4].The gneisses and metasedimentary schist are found mostly as flat lying outcrops [13]. 


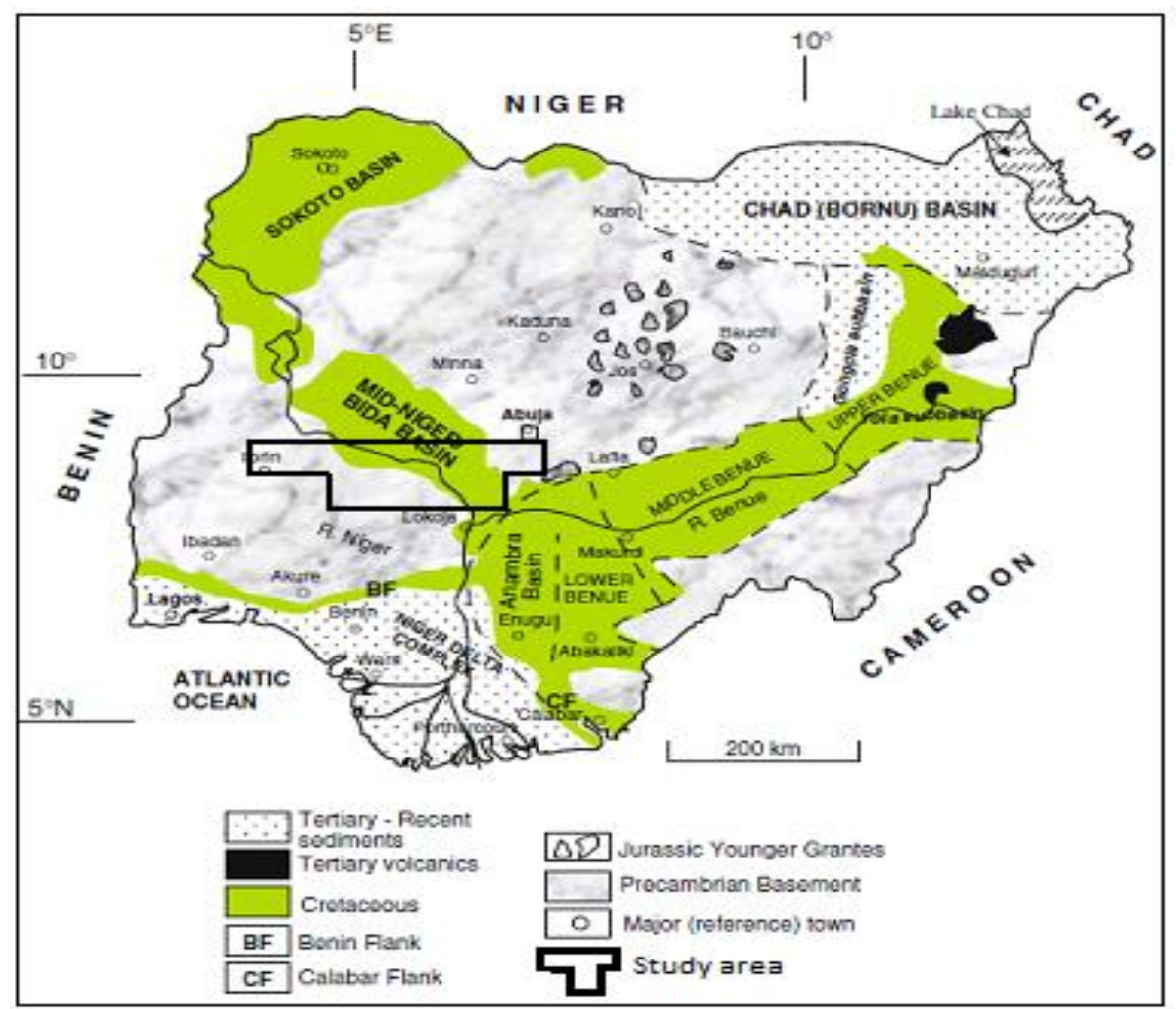

Fig. 1: Geological Map of Nigeria showing the study area (Source: [9])

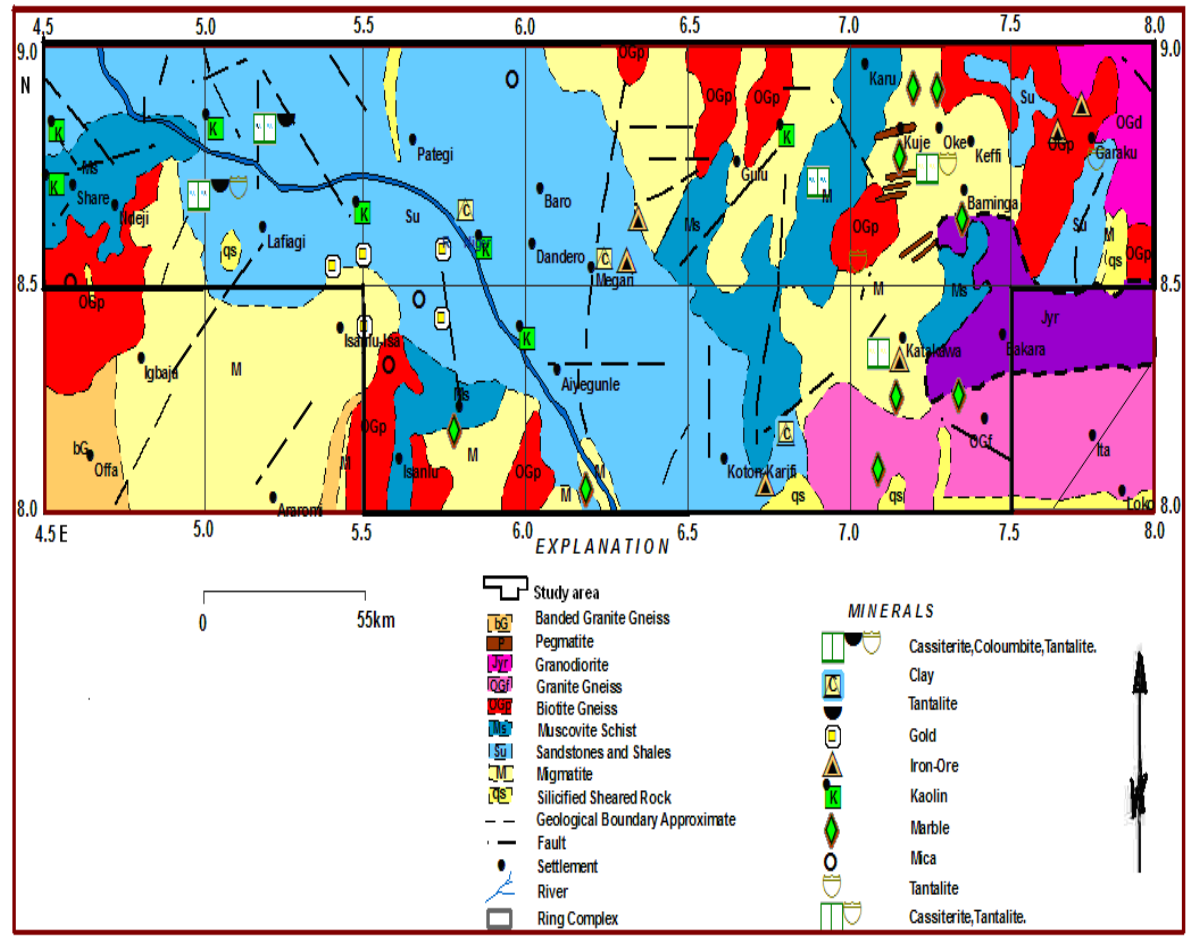

Fig. 2: Geological and Mineral map of the study area (Adapted from the Geological and Mineral Map of Nigeria, 2009, Nigerian Geological Survey Agency).

Structural Geology: Lineaments are major topographical features or geological structures that could be of regional extent usually in linear or curvilinear continuous or discontinuous over an entire length. Lineaments may result from faults, joints, folds, contacts or other geological reasons, and are found in igneous, sedimentary and metamorphic rocks. Lineament-mineral association is possible through the process of mineralization. That is the introduction of minerals 
into pre-existing rocks either in vein placement or in estimated form. Figure 3 is the lineament map of the study area, marked out in black outline. It shows several lineaments trending in various directions namely north-south, east-west, northeast-southwest and northwest-southeast. The red boxes on the map indicate sections of the map where there are cross cutting of lineaments.

The cross cutting of lineaments occurs mostly within the section of the study area covered by the southern Bida basin. As shown in Figure 3 the sections characterised with the cross cutting of lineaments are not zones of mineralization (if they are associated with mineralization, the minerals may be insitu). However, Figure 2 illustrates lineament-mineral association within the research area, as lineaments are observed associated with the occurrence of iron ore and cassiterite around Koton Karfi and Garaku areas, respectively. The work done by Ananaba and Ajakaiye [3], on the evidence of tectonic control on mineralization in Nigeria from lineament density analysis, agrees with this observation. Ananaba and Ajakaiye [3] showed good correlation between areas of high lineament density and the areas where there is occurrence of most

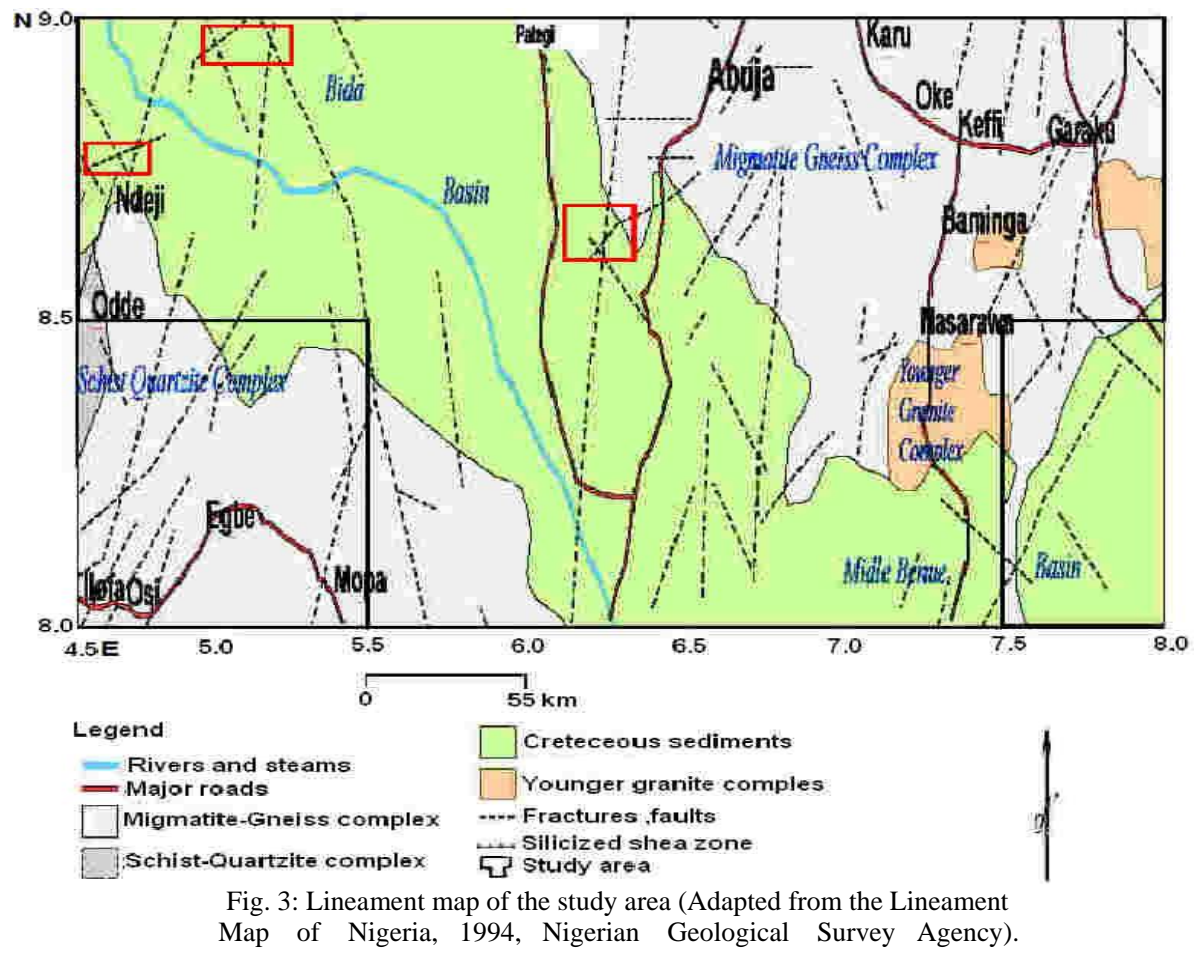

primary minerals such as gold, iron ore, cassiterite, tantalite, clay and uranium. Therefore, the lineament-mineral association suggests that mineralization may be structurally controlled within the study area. Ajakaiye et al. [1] suggested that magnetic lineaments with definite characteristics exist within the Nigerian continental landmass. The magnetic lineaments represent major tectonic trends, which may also continue across the adjoining schist belt region. They further pointed out that this concentration of magnetic lineaments appeared to be connected with the occurrence of younger granites because the trend is prominent in almost all known younger granite complexes. Similarly, Udensi et al. [15] showed that there are lineaments within the Bida basin (Figure 4).

\section{Materials and methods}

\subsection{Materials}

Data acquisition and analysis: The study area is made up of 11 aeromagnetic maps acquired from the Nigerian Geological Survey Agency. These are numbers: 202, 203, 204, 205, 206,207,208, 225, 226, 227 and 228. The magnetic information consists of profiles or flight lines plotted on continuous strip chart. The aeromagnetic data was collected at a nominal flight altitude of $152.4 \mathrm{~m}$ along north-south flight lines spaced approximately $2 \mathrm{~km}$ apart. The airbourne survey data were published in the form of $1 / 2$ degrees by $1 / 2$ degrees contour maps of total magnetic intensity on a scale 
of 1:100,000. The magnetic data was obtained from the digitization of total magnetic intensity contour maps at an interval of 0.0271 units $(\approx 3 \mathrm{~km})$ yielding 2937 data points for the 11 sheets. The $3 \mathrm{~km}$ grid interval imposed a Nyquist frequency of $0.167 \mathrm{~km}^{-1}$.

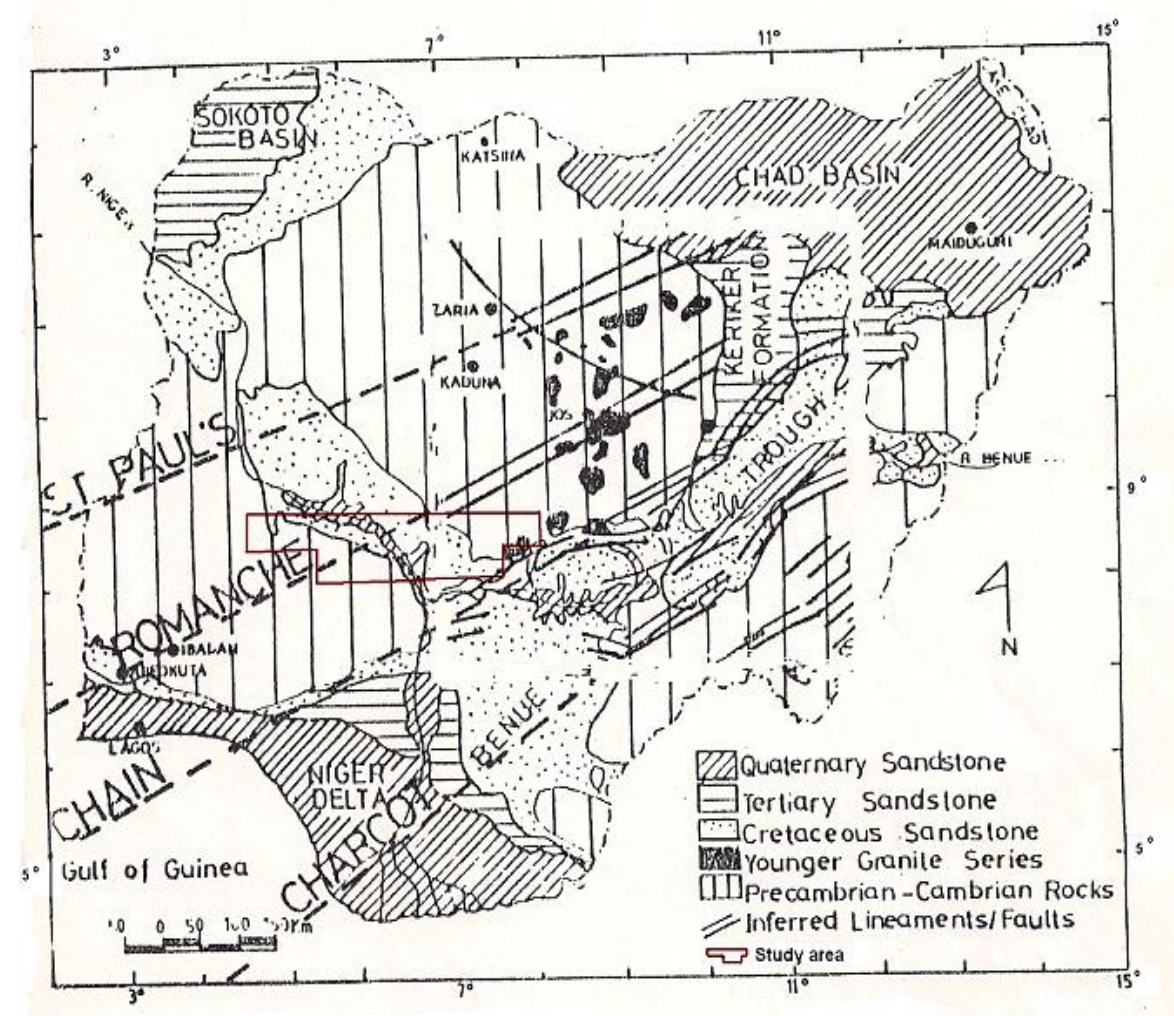

Fig. 4: Structural map of Nigeria showing the St. Paul's, Romanche, Chain and Charcot fracture zones (Source: [15]).

\subsection{Methods}

Euler Deconvolution: The Euler deconvolution method is based on Euler's homogeneity equation; an equation that relates the magnetic field and its gradient components to the location of the source, with the degree of homogeneity $\mathrm{n}$, which may be interpreted as a structural index [14]. The structural index is a measure of the rate of change with distance of a field. For example, in a magnetic field a narrow two dimensional dike has a structural index of $n=1$, while a vertical pipe gives $n=2$.

A solution is recorded if the depth uncertainty of the estimated depth is less than a specified tolerance and the solution is within a limiting distance of the centre of the data window. When the process is stopped, a database file containing the depth solution is obtained as output.

The basic theory of Euler deconvolution technique is given by:-

Any three dimensional function $\mathrm{f}(\mathrm{x}, \mathrm{y}, \mathrm{z})$ is said to be homogeneous of degree $\mathrm{n}$ if the function obeys the expression:

$$
f(t x, t y, t z)=t^{n} f(x, y, z)
$$

from this, it can be shown that the following (known as Euler's equation) is also satisfied:

$$
x \frac{\partial f}{\partial x}+y \frac{\partial f}{\partial y}+z \frac{\partial f}{\partial z}=n f
$$

The degree of homogeneity, $\mathrm{n}$, can be interpreted as a structural index (SI). A magnetic point dipole corresponds to $\mathrm{n}=$ 3 , while a magnetic pole and a line of magnetic dipoles correspond to $n=2$; whereas a magnetic dike and an anomalous 
pipe mass correspond to $\mathrm{n}=1$. Reid et al. [11] have shown that a magnetic contact will yield an index of 0.5 provided that an offset $\mathrm{A}$ is introduced to incorporate anomaly amplitude, strike and dip factors: Where

$$
A=\left(x-x_{0}\right) \frac{\partial T_{f}}{\partial x}+\left(y-y_{0}\right) \frac{\partial T_{f}}{\partial y}+\left(z-z_{0}\right) \frac{\partial T_{f}}{\partial z}
$$

Given a set of observed total field data, we can determine an optimum source location $\left(\mathrm{x}_{0}, \mathrm{y}_{0}, \mathrm{z}_{0}\right)$ by solving Euler's equation for a given index $n$ by least square inversion of the data.

Analytic Signal Technique: Nabighian [7-8] developed the concept of two dimensional analytic signal, or energy envelope, of magnetic anomalies. Roest et al. [12], showed that the amplitude of the three dimensional analytic signal at location $(\mathrm{x}, \mathrm{y})$ can be derived from the three orthogonal gradients of the total magnetic field using the expression:

$$
|A(x, y)|=\left(\left[\frac{d T}{d x}\right]^{2}+\left[\frac{d T}{d y}\right]^{2}+\left[\frac{d T}{d z}\right]^{2}\right)^{1 / 2}
$$

Where

$|A(x, y)|$ is the amplitude of the analytic signal at (x,y)

$\mathrm{T}$ is the observed magnetic field at $(\mathrm{x}, \mathrm{y})$.

The analytic signal anomaly over a two dimensional magnetic contact located at $(x=0)$ and at depth $\mathrm{h}$ is described by the expression [7]:

$$
|A(x, y)|=\alpha \frac{1}{\left(h^{2}+x^{2}\right)^{1 / 2}}
$$

where

$\alpha$ is the amplitude factor

$\alpha=2 M \sin D\left(1-\cos ^{2}\{I\} \sin ^{2}\{A\}\right)$

$\mathrm{h}$ is the depth to the top of the contact

$\mathrm{M}$ is the strength of magnetization

$\mathrm{D}$ is the dip of the contact

I is the inclination of the magnetization vector

$\mathrm{A}$ is the direction of the magnetization vector

The analytic signal described by equation (4) is a bell shaped function in which all directional terms are contained in the amplitude factor á, which is a constant [5]. There, only the amplitude of the analytic signal is affected by the vector components of the model. The shape of the analytic signal is dependent only on depth [5].

Similarly, it can be the analytic signal over a two dimensional magnetic dike as described by the equation:

$$
|A(x, y)|=\alpha \frac{1}{\left(h^{2}+x^{2}\right)}
$$

According to MacLeod et al. [5] the use of a three dimensional presentation is to show how the amplitude of the analytic signal peaks over the edges of the model. The amplitude of the peaks is proportional to the magnetization at that edge as defined by equation (6) [5].

MacLeod et al. [6], showed how the analytic signal could be estimated from the vertical integral of the magnetic field in order to produce a result that is similar to the analytic signal of pseudo gravity. This had the effect of emphasizing deeper or more regional information in the magnetic field and diminishing surface noise. 


\section{Results}

Qualitative Analysis of the Aeromagnetic Data: The plot of the compiled data from aeromagnetic maps digitization yielded Figure 5; which is the total magnetic intensity (TMI) map of the study area. The diagram shows a colour range of total magnetic intensity anomaly values, with red as high and blue as low. The general trending fabric of the total magnetic intensity anomalies is the northeast-southwest direction. The TMI values range from a minimum value of about 7630 nano tesla to a maximum value of about 7930 nano tesla.

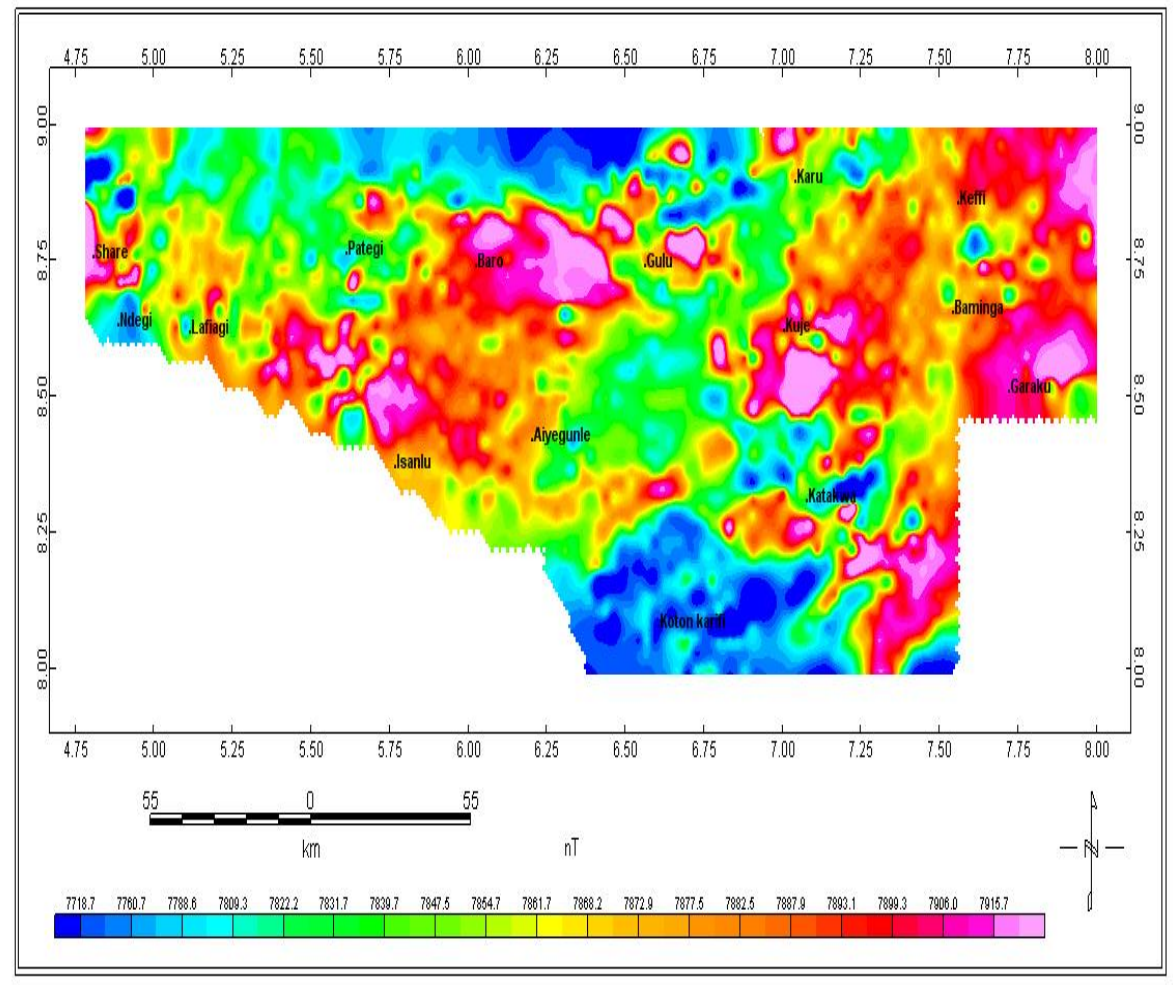

Fig.5: Total magnetic intensity map of the study area. Unit of total magnetic intensity = nano tesla $(\mathrm{nT})$.

The contoured total magnetic intensity map of the study area is shown in Figure 6. It is dominated by swarms of smooth, short wavelength TMI contours. The contours are predominantly nonlinear and incoherent. Figure 7 shows the northeast-southwest trending Romanche Fracture Zone; line (AA), passing through the survey area.

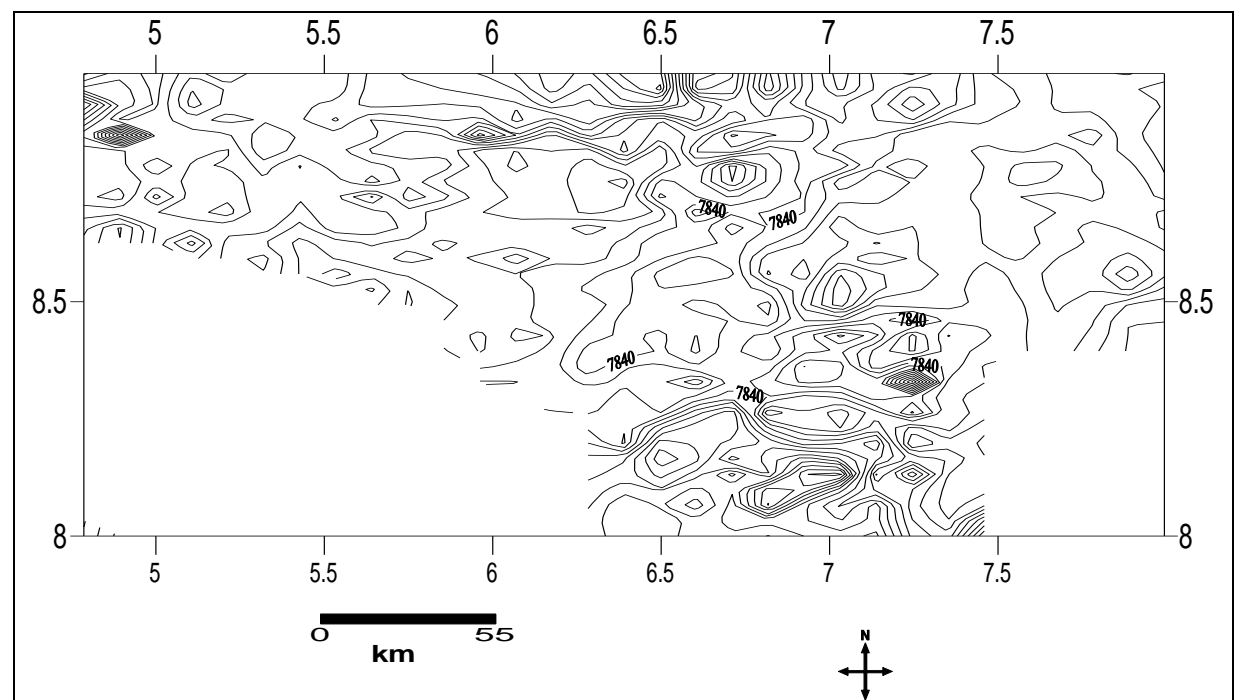

Fig. 6: Contoured total magnetic intensity map of the study area. Unit of total magnetic intensity $=$ nano tesla. Contour interval $=10$ nano tesla 


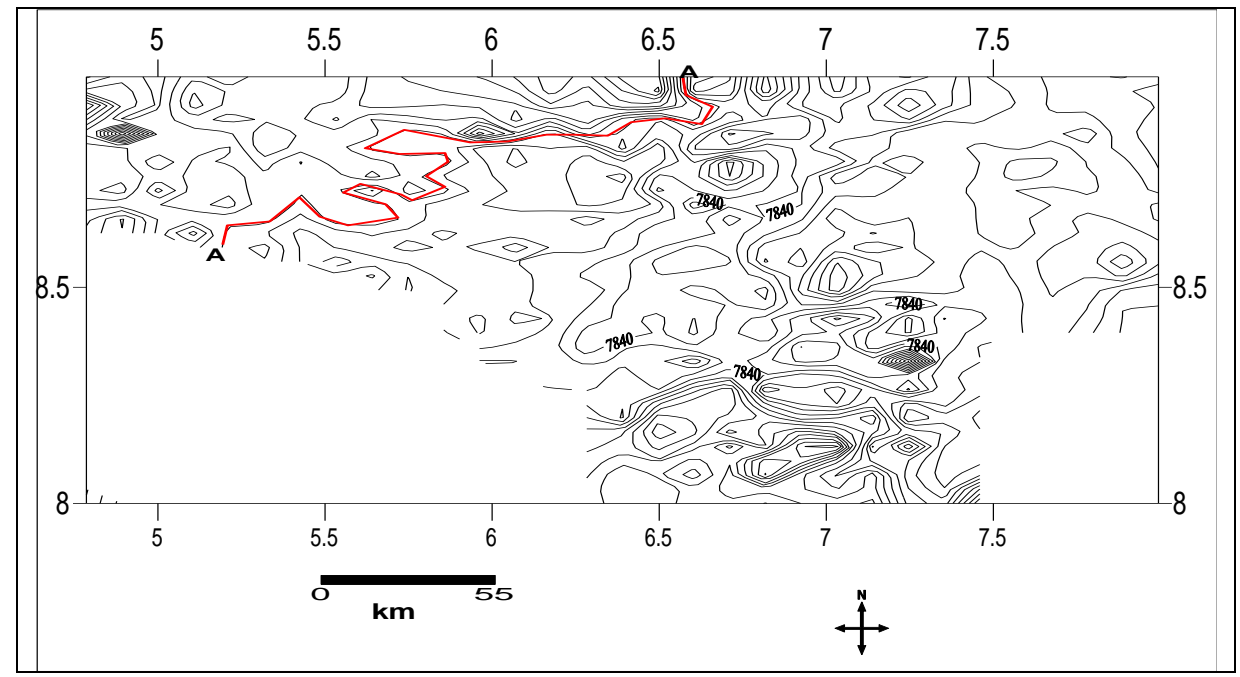

Fig. 7: Contoured total magnetic intensity (TMI) map showing the Romanche fracture zone (AA) passing through the study area. Unit of TMI = nano tesla. Contour interval = 10 nano tesla.

Most rivers courses in the survey area are structurally controlled in the north-south, northwest-southeast and northeastsouthwest directions shown in Figure 8.

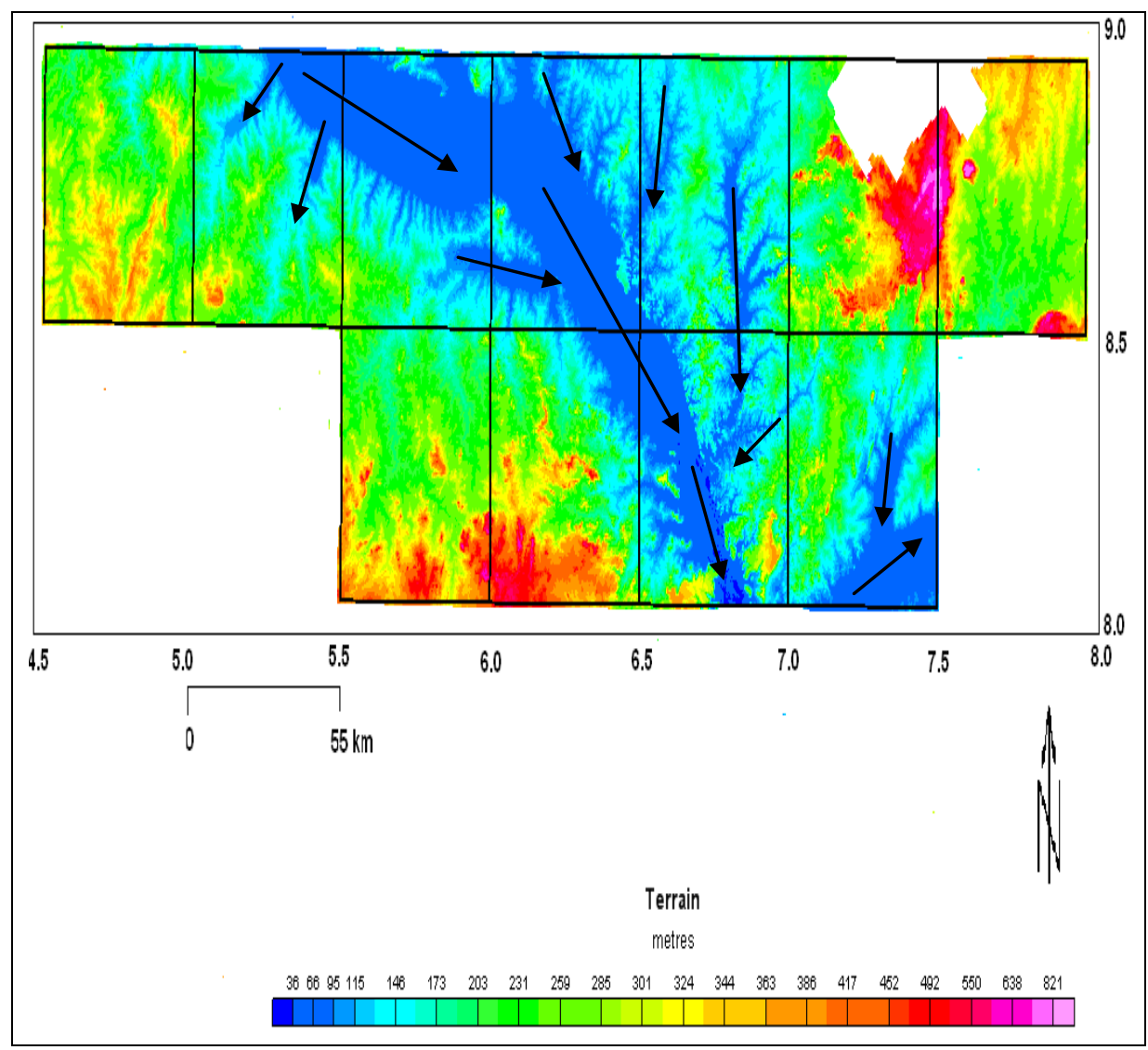

Fig. 8: Terrain map of the study area showing that the drainage pattern is structurally controlled trending predominantly in the north-south, northeast-southwest and northwest-southeast directions. 


\section{Discussion and conclusion}

\subsection{Discussion}

Correlation of zone coloured Euler Deconvolution and Lineament Maps: Figure 9 shows the correlation of both maps on the bases of lineaments. Both maps show lineaments trending in different directions. The prominent trend directions common to both maps are the northeast-southwest and northwest-southeast orientations.

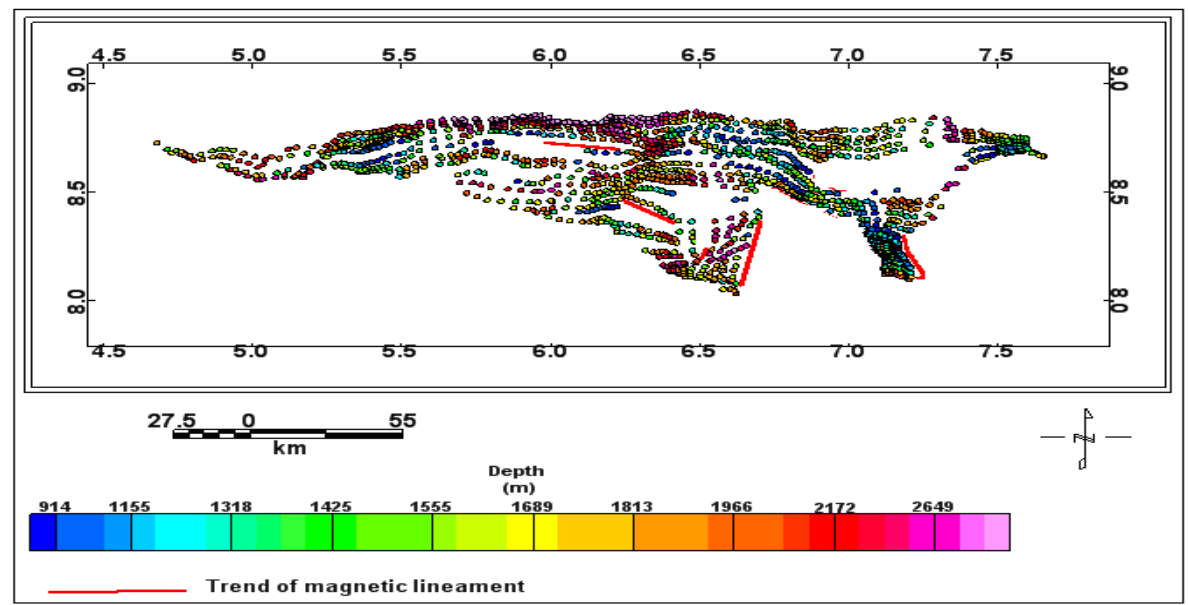

(a) Zone coloured Euler deconvolution map; showing the trends of inferred magnetic lineaments within the study area.

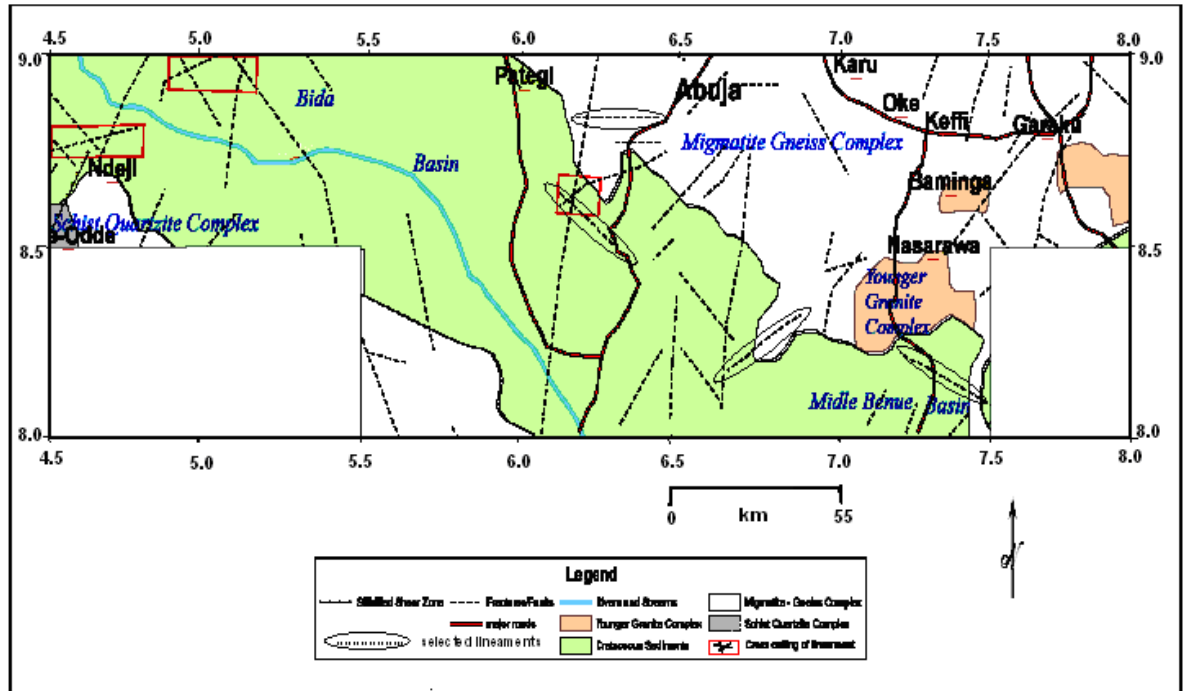

(b) Lineament map of the study area (Adapted from the Lineament Map of Nigeria, 1994, Nigerian Geological Survey Agency)

Fig. 9: Correlation of the zone coloured Euler deconvolution and Lineament maps.

Correlation of the Analytic Signal and Euler Deconvolution maps: The zone coloured Euler deconvolution and analytic signal maps were correlated on the basis of magnetic lineaments, shown in Figures 10 (a) and (b). Both maps showed magnetic lineaments trending in northeast-southwest and northwest-southeast directions. 


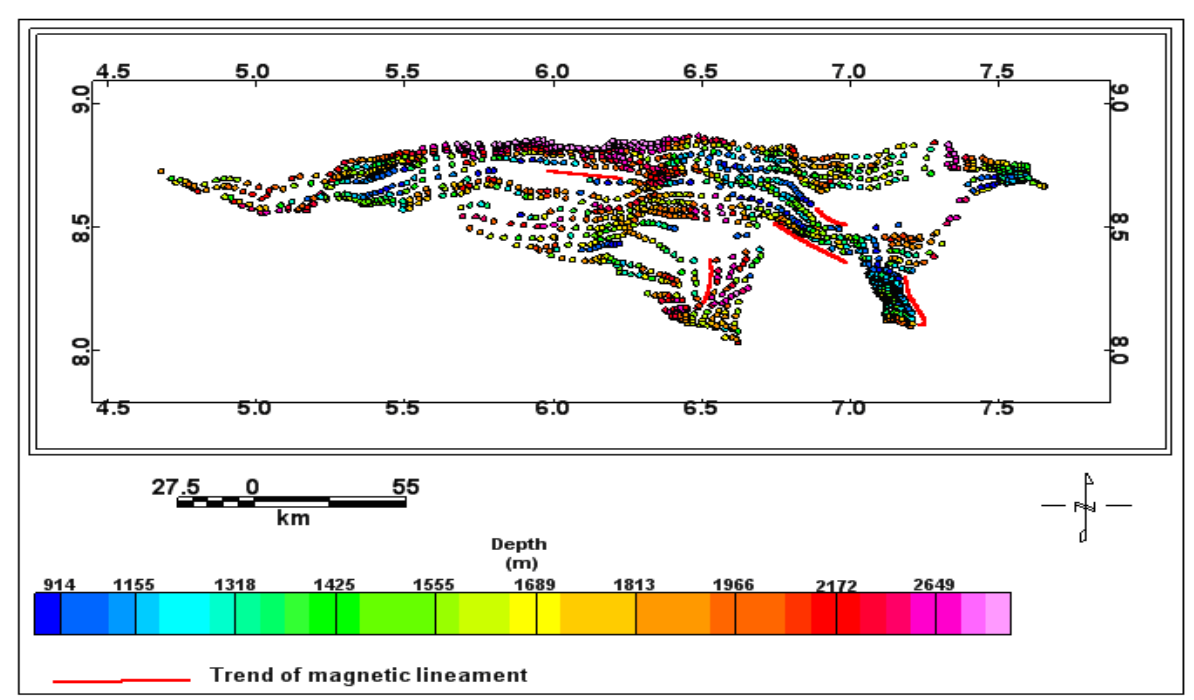

(a) Euler deconvolution map

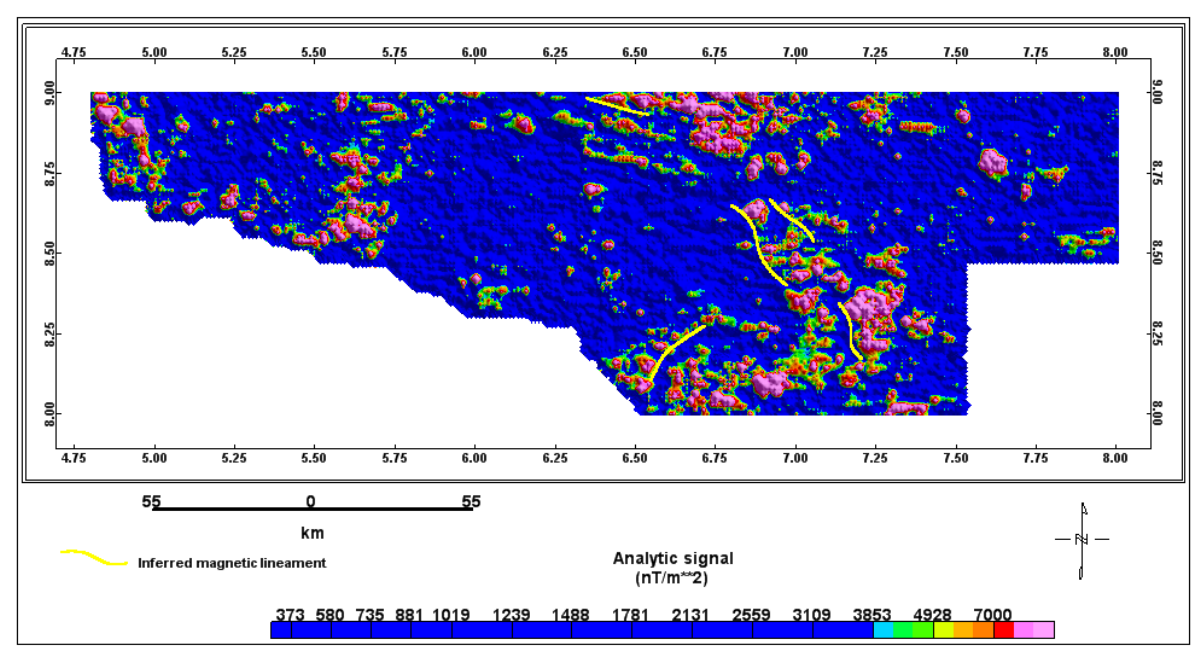

(b) Analytic signal map

Fig. 10: Correlation of (a) zone coloured Euler deconvolution and (b) Analytic signal maps.

\subsection{Conclusion}

The mineralization pattern of the survey area is structurally controlled. Several magnetic lineaments were deduced from the study, and the predominant trends of the lineaments are the east-west, north-south, northeast-southwest and northwest-southeast directions. The northwest-southeast trend reflects the younger tectonic events, because the younger events are more pronounced and tend to obliterate the older events, and thus may indicate recent faulting of country rock. In addition, it is inferred that the northeast-southwest trending Romanche Fracture Zone passed through the survey area.

The linear structures running northeast-southwest observed from the study are suggested as the continental extension of the Pre-Cretaceous oceanic fracture zone; that is, the Romanche Fracture Zone which runs along the trough axis beneath the sedimentary cover. Furthermore, the landward intersections of the lineaments may have influenced the formation of the drainage pattern.

\section{Acknowledgements}

The authors are grateful to the staff of Physics Department, Federal University of Technology, Minna and the staff of the Nigerian Geological Survey Agency, Kaduna, Nigeria for their support and assistance in various capacities. 


\section{References}

[1] Ajakaiye, D. E., Hall, D. H., Ashiekaa, J. A. \& Udensi, E. E. (1991). Magnetic anomalies in the Nigerian continental landmass based on aeromagnetic surveys. Tectonophysics, 192, 211-230.

[2] Akande, S. O., Ojo, O. J., Erdtmann, B. D. \& Hetenyi, M. (2005). Paleoenvironments,organic petrology and rock-eval studies on source rock facies of the Lower Maastrichtian Patti Formation, southern Bida Basin, Nigeria. Journal of African Earth sciences, 41,394-406.

[3] Ananaba, S. E. \& Ajakaiye, D. E. (1987). Evidence of tectonic control of mineralizationin Nigeria from lineament density analysis: A Landsat study, Geology of Nigeria. Lagos: Elizabethan Publishers, pp. 531-537.

[4] Braide, S. P. (1990). Sedimentation and tectonics in the southern Bida Basin, Nigeria. depositional response to varying tectonic context. American Association of Petroleum Geologists (AAPG) Bulletin, 74, 1-20.

[5] Macleod, I. N.,Vierra, S. \& Chaves, A. C.(1993a).Analytic signal and reduction to the pole in the interpretation of total magnetic field data at low magnetic latitudes. Proceedings of the third international congress of the Brazilian society of geophysicists.

[6] Macleod, I. N., Jones, K. \& Dai, T. F, (1993b).Three dimensional analytic signal in the interpretation of total magnetic field data at low magnetic latitudes. Exploration Geophysics, 24, 679-688.

[7] Nabighian, M. N. (1972). The analytic signal of two dimensional bodies with polygonalcross section: Its properties and use for automated anomaly interpretation. Geophysics, 37, 507-517.

[8] Nabighian, M. N. (1974). Additional comments on the analytic signal of two dimensional magnetic bodies with polynomial cross section. Geophysics, 39, 85-92.

[9] Obaje, N. G. (2009). Geology and mineral resources of Nigeria. Berlin: Springer Publishers, pp. 1-203.

[10] Obaje, N. G., Musa, M. K., Odoma, A. N. \& Hamza, H. (2011). The Bida Basin in north central Nigeria: sedimentology and petroleum geology. Journal of Petroleum and Gas Exploration Research, 1(1), 001-013.

[11] Reid, A. B., Allsop, J. M., Granser, H., Millet, A. J. \& Somerton, I. W. (1990).Magnetic interpretation in three dimension using Euler deconvolution. Geophysics, 55, 80-91.

[12] Roest, R. W., Verhoef, J. \& Pilkington, M. (1992). Magnetic interpretation using the three dimensional analytic signal. Geophysics, 57, 116125.

[13] Shekwolo, P. D. (1992). Regional hydrogeology of Bida Basin, Ph.D. Thesis, Ahmadu Bello University, Zaria, Nigeria.

[14] Thompson, D. T. (1982). A new technique for making computer assisted depth estimates from magnetic data. Geophysics, $47,31-37$.

[15] Udensi, E. E., Osazuwa I. B. \& Daniyan, M. A. (2003). Trend analysis of the total magnetic field over the Bida Basin, Nigeria. Nigerian Journal of Physics. 15,143-151. 